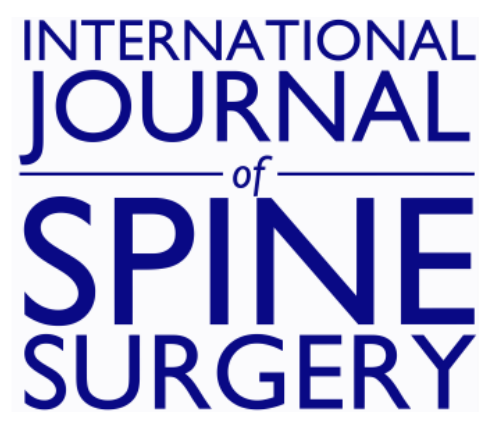

\title{
Traumatic Atlanto-Occipital Dislocation--A Comprehensive Analysis of All Case Series Found in the Spinal Trauma Literature
}

Andrei Fernandes Joaquim, Gregory D. Schroeder and Alexander R. Vaccaro

Int J Spine Surg 2021, 15 (4) 724-739

doi: https://doi.org/10.14444/8095

http://ijssurgery.com/content/15/4/724

This information is current as of April 26, 2023.

Email Alerts Receive free email-alerts when new articles cite this article. Sign up at:

http://ijssurgery.com/alerts

The International Journal of Spine Surgery

2397 Waterbury Circle, Suite 1,

Aurora, IL 60504, Phone: +1-630-375-1432 


\title{
Traumatic Atlanto-Occipital Dislocation-A Comprehensive Analysis of All Case Series Found in the Spinal Trauma Literature
}

\author{
ANDREI FERNANDES JOAQUIM, MD, PhD ${ }^{1}$ GREGORY D. SCHROEDER, MD ${ }^{2}$ \\ ALEXANDER R. VACCARO, MD, PhD, MBA \\ ${ }^{1}$ Department of Neurology, State University of Campinas, Campinas-SP, Brazil, ${ }^{2}$ Department of Orthopaedic Surgery and Neurosurgery at Thomas Jefferson \\ University, Philadelphia, Pennsylvania, ${ }^{3}$ Department of Orthopaedic Surgery and Neurosurgery at Thomas Jefferson University, Philadelphia, Pennsylvania
}

\begin{abstract}
Background: Traumatic atlanto-occipital dislocation (TAOD) is one of the most devastating traumatic injuries, generally associated with immediate death after high-energy trauma. The aim of this study was to perform a systematic literature review of all cases series of TAOD and present the current state of this entity.

Methods: A systematic literature review was performed according to the Preferred Reporting Items for Systematic Reviews and Meta-Analyses (PRISMA) guidelines. Only case series with at least 5 cases were included in the analysis. We focused on survival rates, diagnostic methods, delays in diagnosis, outcomes, and cases successfully treated nonoperatively.

Results: A total of 17 articles were included (16 retrospective and 1 prospective study) with 341 patients. Six studies included pediatric patients only. The mean Glasgow Coma Scale at admission was $\leq 8$ in all studies. Many different diagnostic criteria were used, but none of them had high accuracy. The overall mortality rate was $34.8 \%$, but the studies' designs were heterogeneous (some included only survivors). A high rate of concomitant traumatic brain injury was documented in some studies. We found it interesting that some patients were treated with cervical immobilization $(37 / 341 ; 10.8 \%)$, which was generally used in less unstable injuries; however, the majority of patients were managed with an occipito-cervical fusion (193/341; 56.5\%).

Conclusions: TAOD is a devastating traumatic injury, with a high mortality rate. An MRI may be recommended when there are subtle findings of TAOD and a normal computed tomography scan, such as subarachnoid hemorrhage in the posterior fossa, upper cervical injuries, or consistent neurological findings. Further studies are necessary to identify patients with mild MRI findings and TAOD that may be managed nonoperatively.
\end{abstract}

Cervical Spine

Keywords: atlanto-occipital dislocation, occipito-cervical dislocation, craniocervical dislocation, traumatic, injury

\section{INTRODUCTION}

Traumatic atlanto-occipital dislocation (TAOD), also known as occipital-cervical dislocation, craniocervical dislocation, craniocervical dissociation, or internal decapitation, was first reported in 1908 by Blackwood in regard to a patient with complete neurological deficit with a postmortem analysis reporting an occiput dislocated forward on the spinal column. ${ }^{1}$

TAOD is one of the most severe and devastating traumatic injuries, generally occurring after highenergy traumas; it constitutes up to $31 \%$ of immediate deaths in motor vehicle fatalities according to autopsy studies. ${ }^{2,3,4}$ The death rate is so high that, according to a literature review ${ }^{5}$ published in
2005, only 135 survivors were reported from 19662001.

Historically, many radiological measurements based on simple plain x-rays were used to diagnosis TAOD, but they were clearly insufficient and inadequate to evaluate properly the craniocervical junction (CCJ). ${ }^{6}$ Currently, computed tomography (CT) scan is the exam of choice for initial screening of trauma patients, but even after a CT scan there are some anecdotal cases of delayed diagnosis of TAOD and late neurological deterioration. ${ }^{7-9}$ In addition, management of less-evident forms of TAOD, such as those with only MRI findings and normal or subtle findings on CT scan, require further elucidation because instability is not clear. $^{10,11}$ Finally, clinical presentation may vary 
from normal neurological exam and no spinal cord injury to complete paralysis and respiratory failure and cardiac arrest. This can lead to a wide range of presentations that may make the diagnosis difficult, potentially confounded by the fact that most of these patients may also have severe traumatic brain injury (TBI). ${ }^{12}$

In this context, we performed a comprehensive systematic literature review of clinical studies discussing the characteristics, diagnosis, and management of patients with TAOD.

\section{METHODS}

A systematic literature review was performed according to the Preferred Reporting Items for Systematic Reviews and Meta-Analyses (PRISMA) guidelines. ${ }^{13}$ Only case series with at least 5 cases were included and analyzed, without age limit. We focused on diagnostic methods, delays in diagnosis, the survival rates, neurological outcomes, and cases successfully treated without surgery.

\section{Search Strategy}

Due to the multiple terms used to refer to TAOD, we performed multiple searches in the PubMed database with different strategies. All existing studies up until April 29, 2020, were queried and reviewed. A total of 4 different searches were performed including cross-referenced articles.

The first search was performed using the following key words: "atlanto AND occipital dislocation AND traumatic," obtaining 122 studies, with 13 selected. The second search was performed using the following key words: "cranio AND cervical AND dislocation," obtaining 42 studies with 1 selected. The third search was performed using the key words "occipito AND cervical AND dislocation," obtaining 91 studies, with 3 selected. Finally, a fourth search was performed using the key words "craniocervical AND dissociation," with an additional 4 studies obtained. Six studies were duplicates and thus excluded, for a total of 15 eligible studies. Additional cross-referencing provided 2 more clinical studies, for a total of 17 fully included. A flowchart detailing our search selection is presented in Figure 1.

Methodological Quality Evaluation: Potential risk for bias was assessed according to the Methodological Index for Non-Randomized Studies (MINORS) instrument (whereby fewer than 12 points suggest low-quality studies). ${ }^{14}$ All the studies were then analyzed for internal validity integrity and graded for level of evidence in accordance to the Oxford Centre for Evidence-Based Medicine. ${ }^{15}$

Eligibility Criteria: Clinical case series, retrospective or prospective, with a minimum 5 cases of TAOD were included. Studies should be written in English language; small case series or narrative and systematic reviews were excluded.

\section{Data Collection Process}

One of us (A.F.J.) independently extracted data from the included studies using a piloted data extraction form.

\section{Data Extraction}

The following data were extracted from the included studies, when described: number of patients, study design, patients' characteristics (age, Glasgow Coma Scale [GCS], sex), diagnosis and radiological findings, interventions performed, outcomes and follow-up, results, and survival rates.

\section{RESULTS}

Of the 17 included articles, 16 were retrospective case series (1 was a retrospective case series from a prospective trauma database-level 4 evidence) and only 1 was a prospective study (level 2 evidence)..$^{8-10,12,16-28}$ In Table 1 we summarized all the data extracted from the 17 articles fully included. All studies except 2 had a MINORS score of fewer than 12 points, suggesting high risk for bias (see Table 2). ${ }^{17,24}$

\section{EPIDEMIOLOGY}

A total of 341 patients were included in the studies. Of those, 119 patients died (just before admission or during the follow-up). The overall mortality rate was $34.8 \%$, but it may not reflect the reality, because some studies excluded nonsurvivors or nontreated patients. The survival rate in the oldest included study, published by Cohen et al, ${ }^{16}$ reported $100 \%$ mortality at 1 year. Six of the 17 articles included only children and adolescents, with a total of 78 patients $(78 / 341=22.8 \%$ of the entire patient sample), and there was a mortality rate of $55.1 \%$ (43/78 patients during the studies' followup). $9,12,16,17,20,27$ 


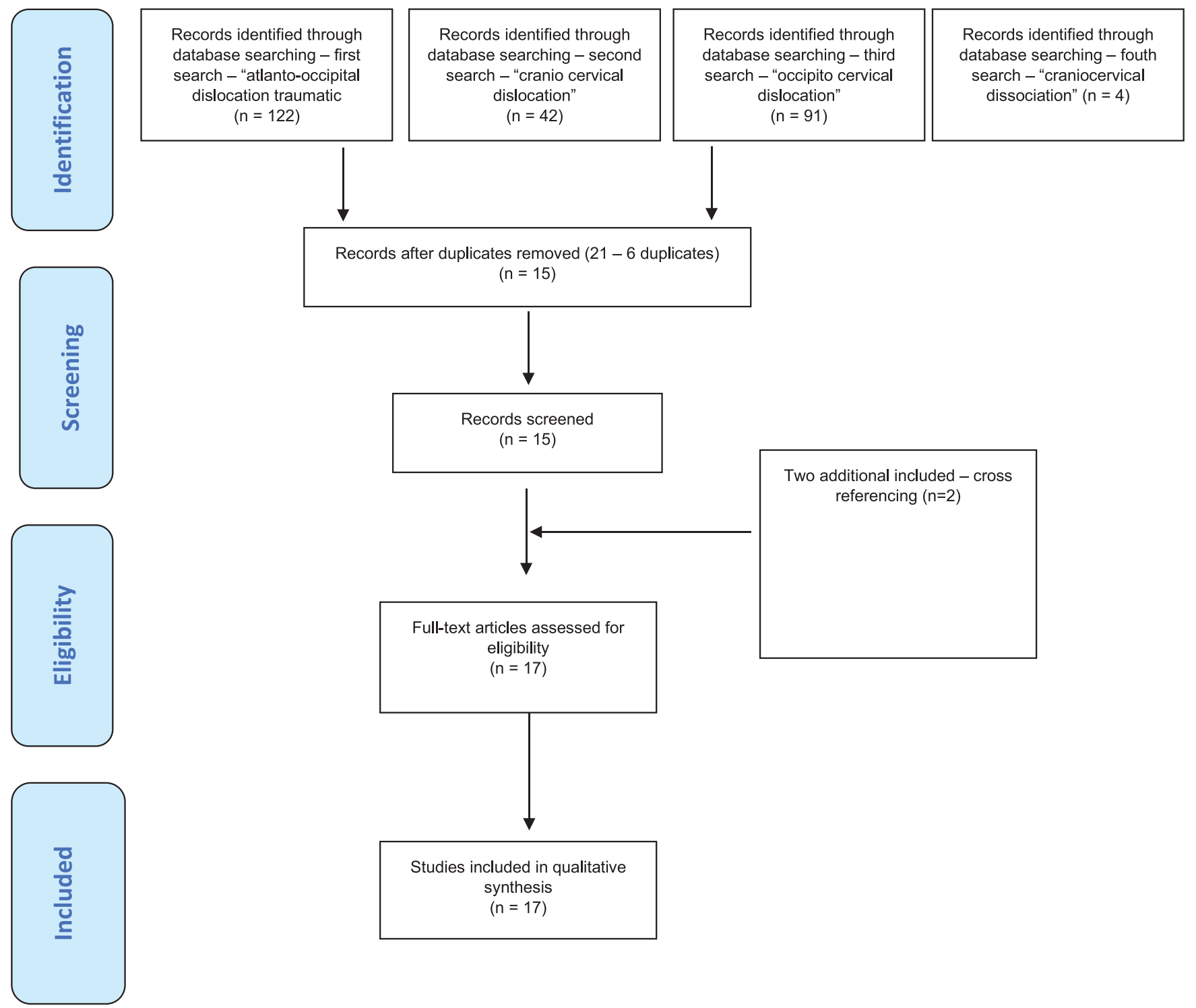

Figure 1. Flowchart diagram of our search mechanism in accordance to the Preferred Reporting Items for Systematic Reviews and Meta-Analyses (PRISMA).

With the exception of 2 studies (both on pediatric patients), all had a majority of patients who were men. ${ }^{12,27}$

Mean GCS at admission, when reported, was 8 points or fewer in all studies, compatible with comatose patients (6.6 points in the Astur et $\mathrm{al}^{9}$ study, 8 points in the Filiberto et $\mathrm{al}^{26}$ study, 7.4 points in the Hosalkar et $\mathrm{al}^{20}$ study). Individual GCS at admission ranged from 3 points (some of the patients were in cardiac arrest) to 15 points in some studies.

Delayed diagnosis was reported in 22 cases, generally with neurological deterioration. ${ }^{8,9,23}$ The study of Reis et $\mathrm{al}^{23}$ reported that delays in diagnosis decreased from 1996-2002 to 2003-2008, suggesting that advances in radiological imaging may increase the diagnosis rate at admission. Of note, the criteria for delayed diagnosis were not clear in the studies. We inferred that early diagnoses were those made immediately after the initial radiological evaluation.

\section{RADIOLOGICAL FINDINGS}

We noted a tremendous heterogeneity in the diagnostic criteria used in the included studies. In 2 of the studies, radiological methods to diagnose were not detailed: Hosalkar et $\mathrm{al}^{20}$ reported that the diagnosis was made using the Power ratio, the Kaufman method, and the Harris method. Filiberto et $\mathrm{al}^{26}$ reported that diagnosis was made by an attending neuroradiologist using CT or MRI scans. 
Joaquim et al.

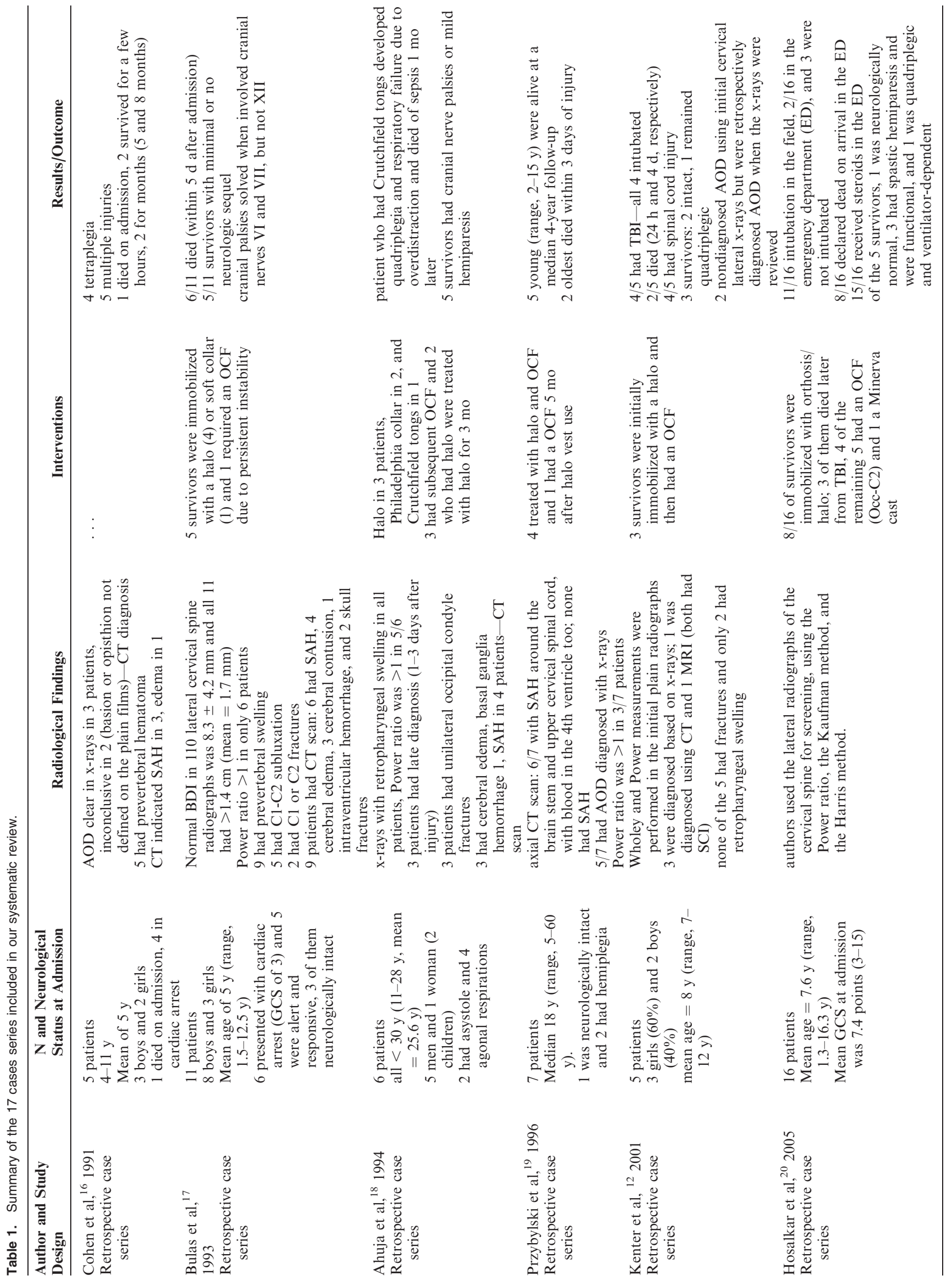




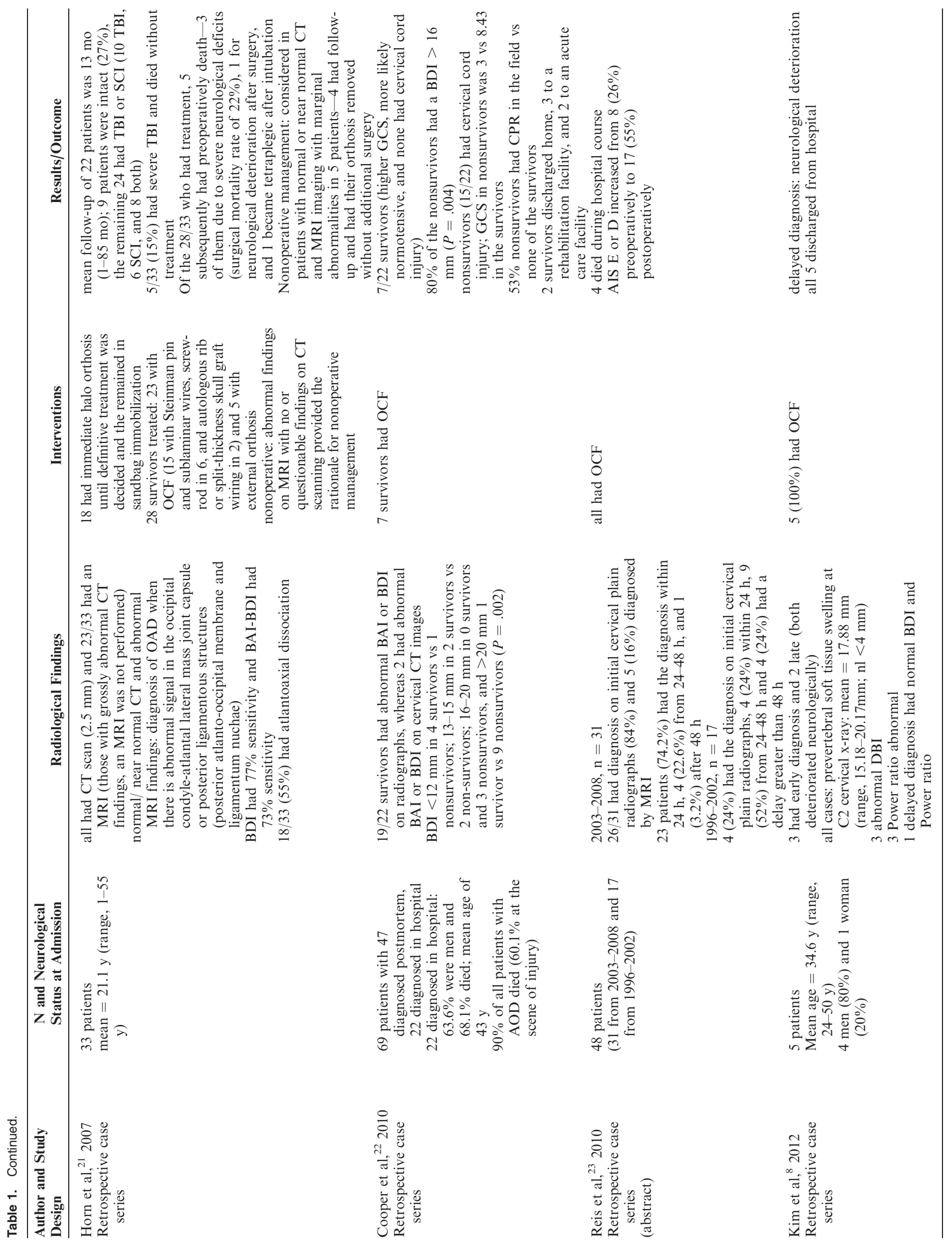




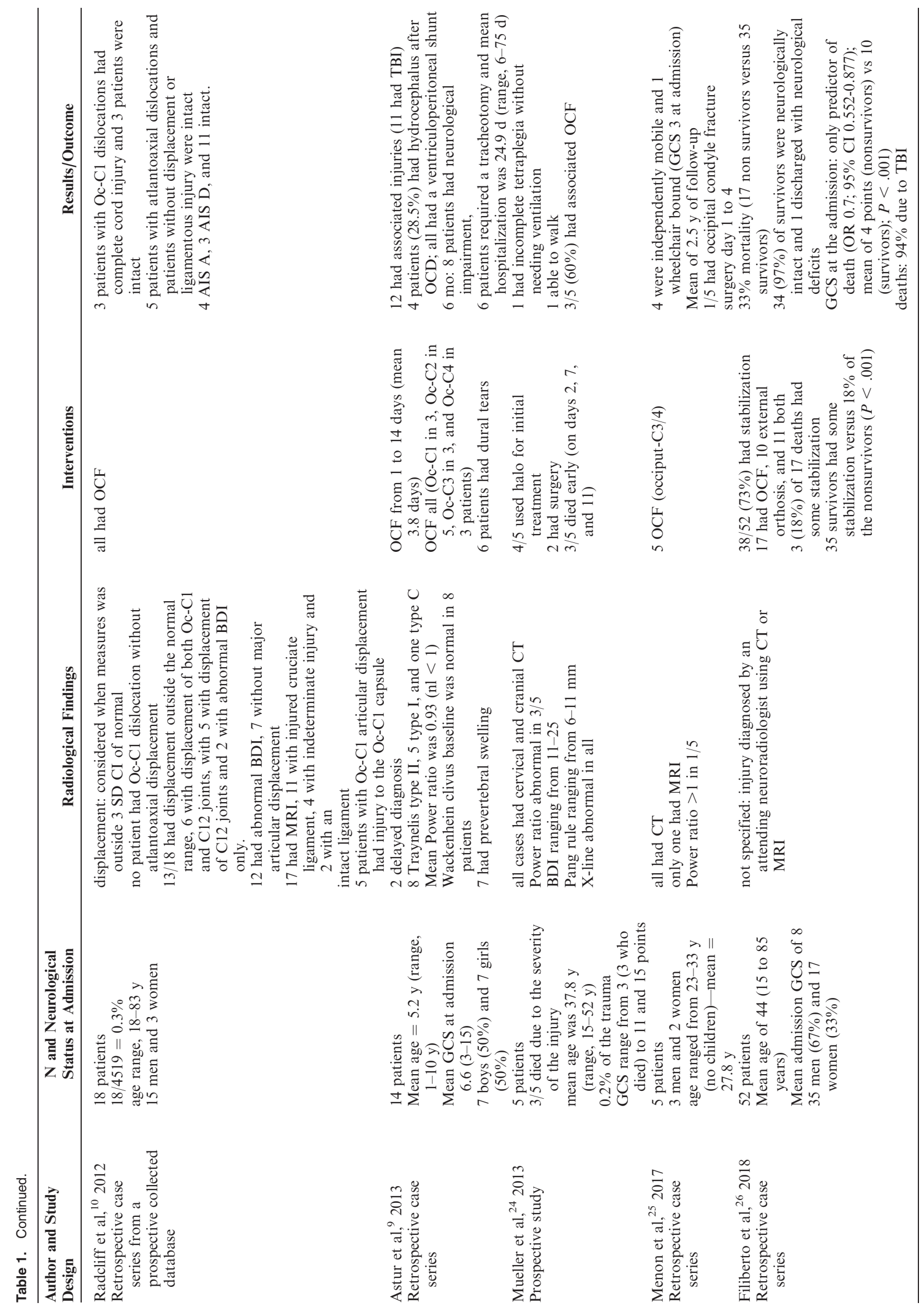




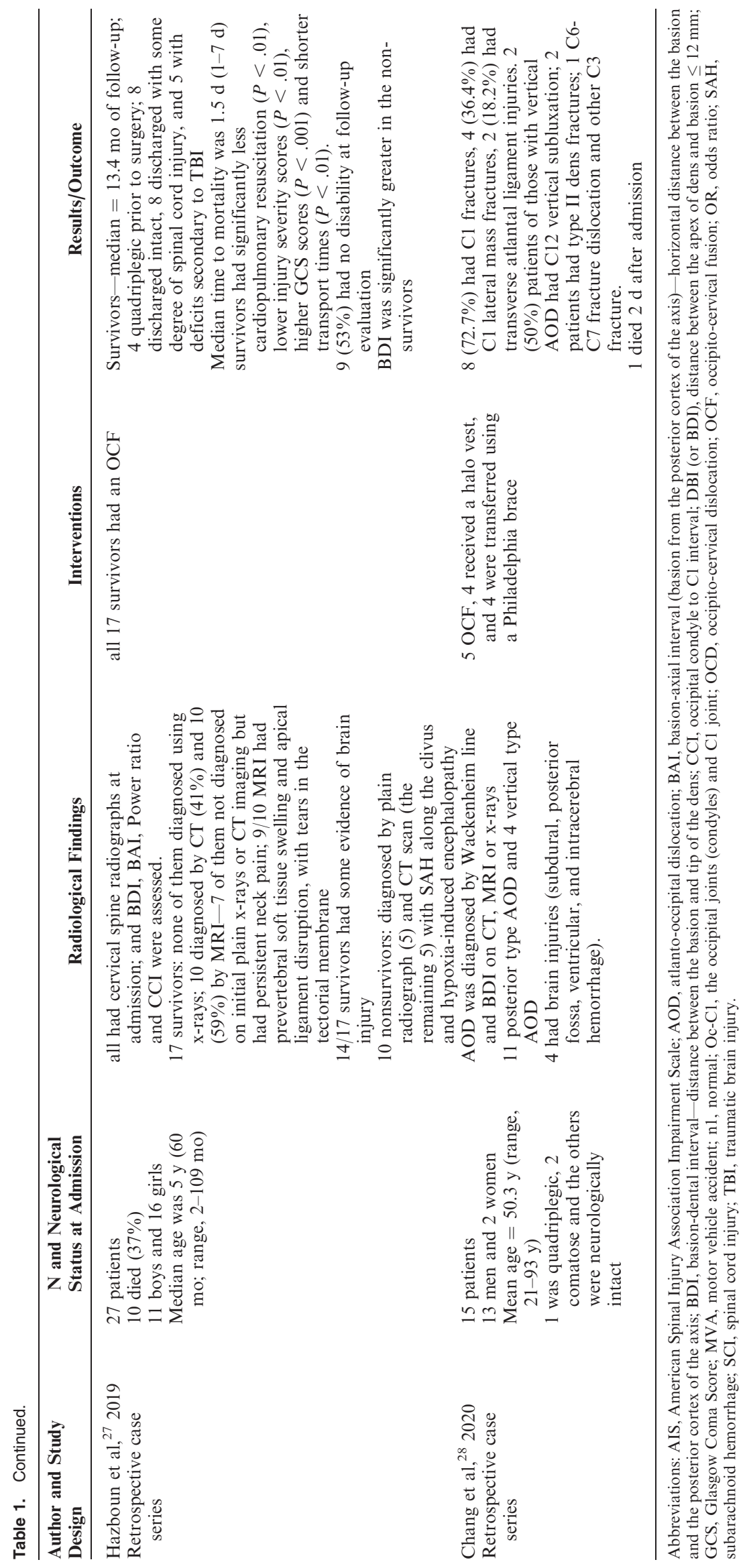




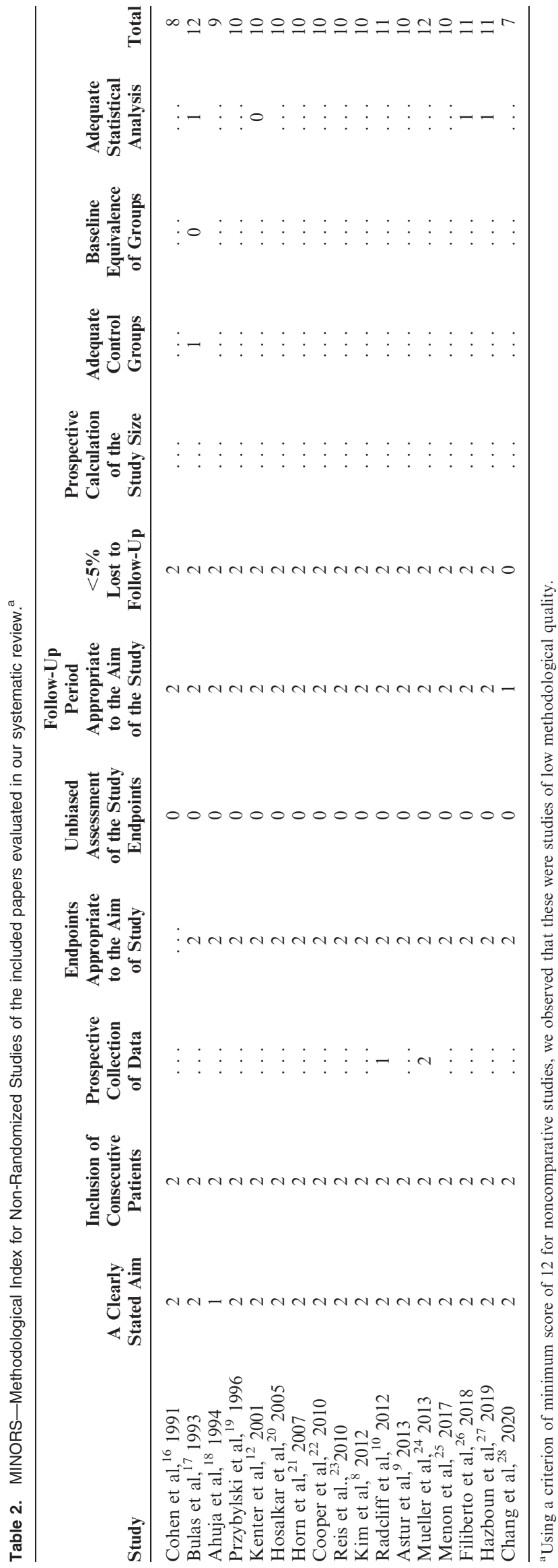

We summarized some of the most-used radiological criteria, as well as their descriptions, in Table 3.

Cohen et al, ${ }^{16}$ in the oldest published study (1991) included in our review, reported that 2 of $5(40 \%)$ patients had inconclusive $\mathrm{x}$-rays due to limitation in the visualization of the basion and opisthion. It is interesting that 5 of $5(100 \%)$ patients had a prevertebral hematoma. This study included only children. The same rate of retropharyngeal swelling was reported by Ahuja et $\mathrm{al}^{18}$; all 6 children had retropharyngeal swelling at the x-rays. On the other hand, only 2 of $5(40 \%)$ children included in the Kenter et al ${ }^{12}$ study had retropharyngeal swelling, with contradictory incidences.

Bulas et $\mathrm{al}^{17}$ also reported a high rate of prevertebral hematoma $(9 / 11 ; 81.8 \%)$ in their series. All 11 patients had a basion-dens interval (BDI) $>$ $1.4 \mathrm{~cm}$ (the normal BDI, according to the authors and based on 110 normal lateral cervical radiographs used as controls, was $8.3 \pm 4.2 \mathrm{~mm}$ ). We found it interesting that the Power ratio was abnormal $(>1)$ in 6 of 11 patients $(54.5 \%)$; comparatively, the Power ratio was abnormal in 3 of $5(60 \%)$ of the patients in the Mueller et $\mathrm{al}^{24}$ study, 1 of 5 patients $(20 \%)$ in the Menon et $\mathrm{al}^{25}$ study, and 3 of $5(60 \%)$ patients in the Kim et $\mathrm{al}^{8}$ study.

Cooper et $\mathrm{al}^{22}$ reported that a BDI $\geq 16 \mathrm{~mm}$ was associated with nonsurvivors $(P=.004)$, and 21 of 22 patients had an abnormal BDI or basion-axis interval (BAI) - the exception was 1 patient with $\mathrm{C} 0-\mathrm{C} 1$ widening despite a normal BDI and BAI. ${ }^{22}$ The same comparison was performed in the study of Hazboun et $\mathrm{al}^{27}$ who reported a higher BDI in nonsurviving pediatric patients than in those who survived. $^{27}$

A high rate of upper cervical spine injuries were associated with TAOD in some articles, similarly to TBI, such as occipital condyle fractures, C1-C2 subluxation, $\mathrm{C} 1$ and $\mathrm{C} 2$ fractures, and transverse atlantal ligament injuries, among others. ${ }^{17,18,28}$ Bulas et $\mathrm{a}^{17}$ reported that $50 \%$ of their patients (3/6) had unilateral occipital condyle fractures.

The following diagnostic criteria were used or cited in the included studies: BDI and BAI, Power ratio, Wholey method, prevertebral swelling, Kaufman method, Harris method, MRI findings of ligamentous injuries, displacement outside 3 SDs of normal measurements of the $\mathrm{C} 0-\mathrm{C} 1$ joints, the Wackenhein clivus baseline, and finally, the Pang rule. 
Table 3. Summary of the mainly used diagnosis criteria for traumatic atlanto-occipital dislocation (TAOD) in the included studies as well as their description.

\begin{tabular}{|c|c|}
\hline Criteria & Radiological Description \\
\hline $\mathrm{BAI}^{29,30}$ & Basion-axial interval-distance of the basion from the posterior cortex of the axis \\
\hline BDI (Wholey method) ${ }^{31}$ & $\begin{array}{l}\text { Basion-dens interval (also described as DBI: dens-basion interval) - distance from the tip of the } \\
\text { dens to the basion - normal range }<10 \mathrm{~mm}\end{array}$ \\
\hline Power ratio ${ }^{32}$ & $\begin{array}{l}\text { Ratio between the distance from the basion and the posterior spinolaminar line of the atlas/the distance } \\
\text { from the opisthion and the anterior arch of the atlas }(>1 \text { - anterior TAOD should be suspected) }\end{array}$ \\
\hline Prevertebral swelling & Generally $<10 \mathrm{~mm}$ in the upper cervical spine \\
\hline Kaufman method ${ }^{21}$ & $\begin{array}{l}\text { The actual distance between the occipital condyle and the condylar facet of } \mathrm{C} 1 \text { (the normal range } \\
\text { width of the atlanto-occipital junction is never }>5 \mathrm{~mm} \text { ) }\end{array}$ \\
\hline Harris method ${ }^{21}$ & $\begin{array}{l}\text { BAI in children was more reliable due to the lack of ossification of the dens before } 12 \text { y of age. } \\
\text { Normal BAI extends from } 12 \mathrm{~mm} \text { anterior to } 4 \mathrm{~mm} \text { to the posterior axial line }\end{array}$ \\
\hline MRI findings of ligamentous injury ${ }^{7}$ & Direct visualization of ligamentous injuries or lack of articular congruence in the MRI \\
\hline Pang rule: the condyle- $\mathrm{Cl}$ interval ${ }^{33}$ & $\begin{array}{l}\text { CCI is the measurement of the interval between the occipital condyle and C1 at } 4 \text { equidistant points } \\
\text { on the joint surface in sagittal and coronal reconstructions of CT (a total of } 8 \text { measurements for } \\
\text { each patient). The true CCI consisted in the mean of the } 8 \text { readings for both sides in coronal and } \\
\text { sagittal images; with a cutoff of } 4 \mathrm{~mm} \text { (the CCI is highly symmetrical in children). }\end{array}$ \\
\hline Traynelis classification $^{35}$ & $\begin{array}{l}\text { Type I-anterior dislocation of the cranium, type II-vertical dislocation/distraction, and type III- } \\
\text { posterior dislocation }\end{array}$ \\
\hline
\end{tabular}

Hazboun et $\mathrm{al}^{27}$ reported that some patients $(7 /$ $17 ; 41.1 \%$ ) were not diagnosed after $\mathrm{x}$-rays and CT scan but due to persistent neck pain underwent an MRI, and this identified TAOD. This was the only study emphasizing a high failure rate on diagnosing TAOD with $\mathrm{x}$-rays and $\mathrm{CT}$ requiring MRI.

\section{TRAUMATIC BRAIN INJURIES}

Many studies reported a high rate of TBI associated with TAOD. Cohen et $\mathrm{al}^{16}$ reported 3 of 5 patients $(60 \%)$ with subarachnoid hemorrhage (SAH) and 1 patient with brain edema evident in the brain CT scan. In their series of 6 patients, Ahuja et $\mathrm{al}^{18}$ documented 3 patients with cerebral edema, 1 with intracerebral hemorrhage, and 4 with SAH. In the Przybylski et al ${ }^{19}$ study, 6 of 7 patients had SAH $(85.7 \%)$. Eleven of $15(73.3 \%)$ had TBI in the Astur et $\mathrm{al}^{9}$ study of pediatric patients. It interested us that in their study, 4 pediatric patients $(28.5 \%)$ with TAOD required a ventriculoperitoneal shunt for hydrocephalus. ${ }^{9}$

In the Hazbound et $\mathrm{al}^{27}$ study, CT scan findings were more evident and severe, even with hypoxia induced by encephalopathy, in nonsurvivors (10/10 had brain CT scan changes).

Finally, in the most recent included study by Chang et $\mathrm{al}^{28}$ in 2020 with 15 patients, 4 had intracranial injuries.

\section{NEUROLOGICAL STATUS}

Of the 222 survivors (65.1\%), about 46.8\% (104) were neurologically intact or almost intact (mild deficits); $11.2 \%$ (25) had severe deficits, tetraplegia, and/or ventilator dependence, and in $41.8 \%$ (93) the details of the neurological status in the follow-up were not obtained. Some studies reported neurological deficits due to TBI alone or associated with spinal cord injury, which were not always possible to characterize in detail. ${ }^{21,26}$

We found it curious that many studies ${ }^{16,18,22}$ reported cardiac arrest in the emergency room or just after admission.

\section{MANAGEMENT}

When treatment was mentioned, an occipitocervical fusion (OCF) was performed in 193 patients, with or without a postoperative cervical orthosis or halo. If we included all 341 patients, $56.5 \%$ were able to receive an OCF. On the other hand, 37 patients $(10.8 \% ; 37 / 341)$ were treated with a cervical orthosis, halo vest, or Crutchfield tongs and did not have surgery. In a series of 33 patients of Horn et $\mathrm{al}^{21}{ }^{21}$ the rationale for nonoperative management was clarified: patients with abnormal findings on MRI with no or minimal injuries evident on CT scans. Five patients were treated according to these criteria and 4 had follow-up; none of them required further surgery.

A total of 341 patients were included in the studies. Of these, 119 patients died (just before admission or during the follow-up). The overall mortality rate was $34.8 \%$, but it may not reflect the reality, because some studies excluded nonsurvivors or nontreated patients. The survival rate in the oldest included study, published by Cohen et al, ${ }^{16}$ reported $100 \%$ mortality in 1 year. $^{16}$ of the 17 articles, 6 included only children and adolescents, with a total of 78 patients $(78 / 341=22.8 \%$ of the entire patient 
sample) and a mortality rate of $55.1 \%$ (43 patients during the studies' follow-up). ${ }^{9,12,16,17,20,27}$

\section{DISCUSSION}

We performed one of the most comprehensive systematic literature reviews of TAOD. Despite its limitations from including different study designs, such as some studies evaluating only survivors and others including all patients with a diagnosis of TAOD, it provides some interesting insights about this rare but devastating entity. It is widely known that TAOD should be treated surgically in the vast majority of patients as soon as possible. The mortality rate of $34.8 \%$, reaching up to $68.7 \%$ in an isolated study, is quite high. ${ }^{20}$ TAOD generally affects men, who present as comatose and with concomitant TBI at the emergency department, despite a small number of patients who may be neurologically intact. In children, it seems to affect equally boys and girls. ${ }^{2,11}$

Zivot et $\mathrm{al}^{4}$ reported 26 of $85(31 \%)$ atlantooccipital dislocations as the immediate cause of death in fatal motor vehicle-pedestrian accidents. ${ }^{4}$ The instantaneous death may be due to brainstem injury, resulting in vascular and neurogenic shock, respiratory failure, and immediate death, potentiated by concomitant injuries, such as TBI or multisystem trauma. In the retrospective study of a prospectively collected database included in our review, Radcliff et $\mathrm{al}^{10}$ reported that the incidence of TAOD among all spinal traumas in their institution was 18 patients of a total of 4519 spinal trauma cases - representing $0.3 \%$ of the entire sample.

Children are more susceptible to TAOD than adults, and, in our review, they also had a higher mortality rate. There are potential reasons for a higher incidence of TAOD in this age group: a higher relationship between head size/spine proportion (the head size/ spine proportion is substantially larger in children than in adults), the immature composition of the spine (more mobile osseous and musculoligamentous composition), and the plane of the atlanto-occipital joint, which is practically horizontal with small condyles. All these reasons together may put children at a higher risk of TAOD. ${ }^{16,35}$ We also believe that the lower bone density facilitates ligamentous injuries instead of bone fractures, explaining a higher rate of ligamentous injury in children than in adults.

Theodore et $\mathrm{al}^{36}$ reported in a systematic review that nearly $20 \%$ of the patients with acute TAOD had a normal neurological exam at admission. Although the final outcome was not detailed in all included articles, overall they reported that $46.8 \%$ of patients were neurologically intact or presented with mild deficits at the last follow-up or at hospital discharge, compared with $11.2 \%$ patients who were severely disabled (in $41.8 \%$ of the cases details of the clinical outcome were not provided). For this reason, early detection and treatment is paramount for patients who survive initial trauma and are able to receive prehospitalar care. In many studies, ${ }^{17,18}$ cranial nerve palsies were also documented, most with clinical improvement over time. The most common cranial nerve injuries associated with TAOD described were to the VI, VII, and XII. The potential explanations for these injuries are sudden distraction or even injury to the nerve nuclei itself in the brainstem. ${ }^{?}$

\section{Radiological Methods to Diagnose TAOD}

In our review, there was a tremendous heterogeneity in the radiological methods used to diagnose TAOD. This was also consistent with the pertinent literature about challenges in the radiological diagnosis of TAOD. There were many proposed plain radiographic methods to diagnose TAOD. The most used included (1) a displacement of more than $10 \mathrm{~mm}$ between the basion and tip of the dens - the $\mathrm{BDI}^{31}$; (2) the ratio of the basion to the midpoint of the anterior cortex of the posterior arch of $\mathrm{C} 1$ distance divided by the ratio of the opisthion to the midpoint of the posterior cortex of the anterior arch of $\mathrm{C} 1$, which should be greater than 1 to diagnose-Power ratio ${ }^{37}$; (3) a distance from the posterior mandible and anterior atlas of more than $13 \mathrm{~mm}$ or a distance from the posterior mandible and dens of more than $20 \mathrm{~mm}^{38}$; (4) Failure of a line from the basion to the axis spinolaminar junction to intersect $\mathrm{C} 2$ or a line from the opisthion to the posterior inferior corner of the body of the axis to intersect $\mathrm{C} 1$ - the X-line method ${ }^{30}$; (5) a displacement of more than $12 \mathrm{~mm}$ or less than $4 \mathrm{~mm}$ between the basion and posterior $\mathrm{C} 2$ line (BAI) or a displacement of more than $12 \mathrm{~mm}$ from the basion to the dens (BDI). ${ }^{32}$ These measurements included studies published in 1958 and 1979, with the newest one published in 1994, which did not consider the quality of modern CT scan image and reconstructions. The limitations to proper bone and joints evaluation, as well as the low sensitivity (about 0.505 ) and specificity of $x$-rays in diagnosing TAOD 


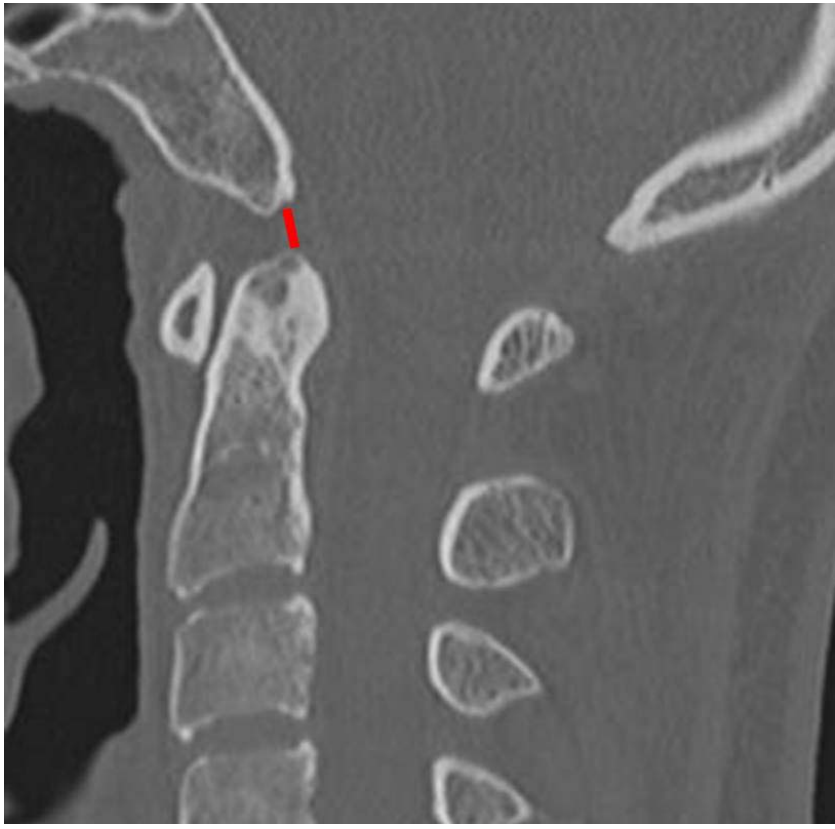

Figure 2. Sagittal midline computed tomography (CT) scan measuring the distance from the basion to the tip of the dens-the basion-dens interval. Normal values from adults' CT scans are $<8.5 \mathrm{~mm}$ in $95 \%$ of the cases. ${ }^{44}$

(as well as other cervical injuries), are widely known. ${ }^{36}$ For this reason, in the modern spinaltrauma era, we believe that plain radiographs to diagnose TAOD have only historical value. Recently, a radiological protocol proposed by the Spinal Cord Society concluded that a multidetector CT scan with reformatted images is the initial line of imaging for trauma patients and radiographs should be used only if CT is unavailable or unaffordable. In the same position statement protocol, they suggested that MRI should be indicated in patients with neurological involvement and advanced cervical degenerative changes to evaluate epidural-space compromise, disco-ligamentous injury, and also soft tissue injuries. ${ }^{7}$ Figures $2-4$ illustrate the most important radiological measurements for diagnosing TAOD.

In 2013, a guideline of the American Association of Neurological Surgeons concluded that initial lateral cervical radiographs may miss the diagnosis of TAOD, which was also observed in some cases published in our review, resulting in later neurological deficit. ${ }^{36}$ By that time, they suggested that a high index of suspicion should be maintained in patients with prevertebral soft tissue swelling on "normal" lateral x-rays or in patients with craniocervical SAH on axial CT images. They also stated that there was a high level of evidence to use the condyle-C1 interval $(\mathrm{CCI})$ in pediatric patients to diagnosis TAOD. This index was published by Pang et $\mathrm{al}^{33}$ with a sensitivity and specificity of $100 \%$ compared with standard tests on plain films that had sensitivities varying from $25 \%-50 \%$ and specificities from $10 \%-60 \%$ in diagnosing TAOD.
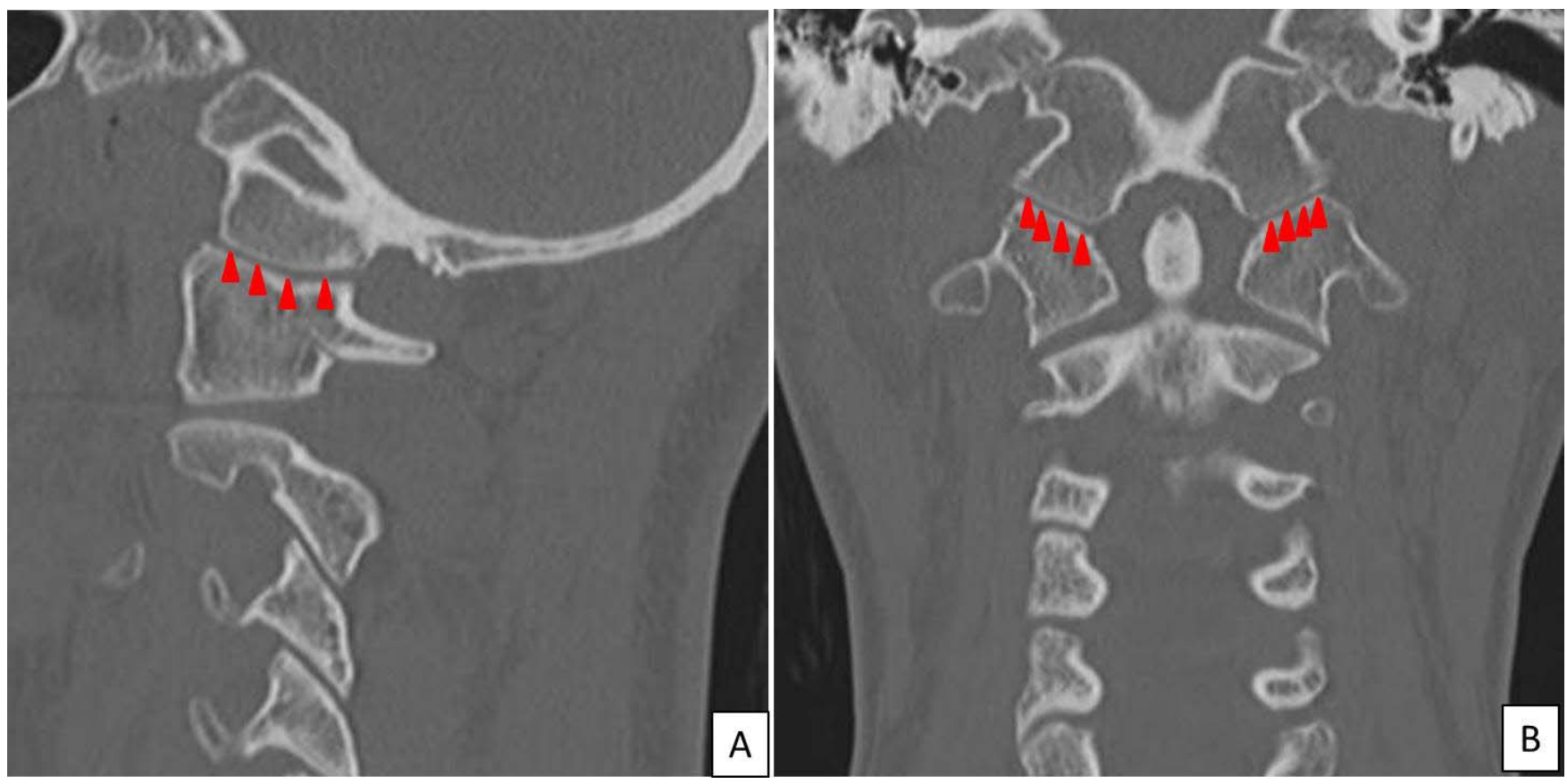

Figure 3. (A) Sagittal and (B) coronal computed tomography (CT) scan reconstructions-4 equidistant points were marked on the articulating surfaces of the occiput$\mathrm{C} 1$ joint that encompassed the broadest joint surface. The joint interval at each point was recorded and the mean of these 8 measurements (from both sides and from sagittal and coronal CT scans) are the true condyle-C1 interval (CCI). ${ }^{39}$ 


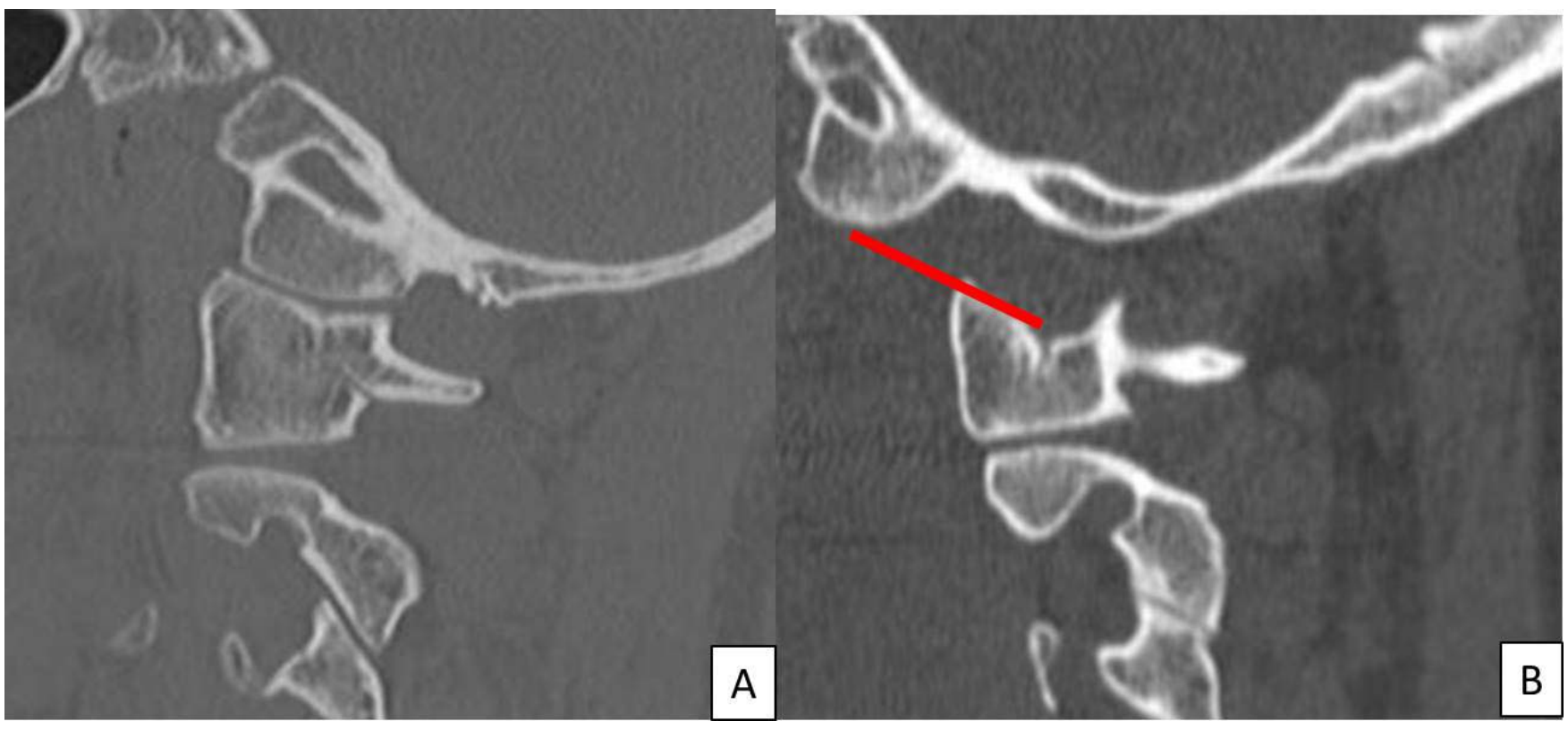

Figure 4. Sagittal CT scan (A) of a normal and (B) of a patient with a traumatic atlanto-occipital dislocation (TAOD). The red line in $B$ represents the revised condyle$\mathrm{C} 1$ interval $(\mathrm{CCl})$. The diagnosis of TAOD is made when distance at the point of great separation of the $\mathrm{C} 1$ lateral mass from the occipital condyle is greater than 2.5 $\mathrm{mm}^{44}$

The CCI is the measurement of the interval between the occipital condyle and $\mathrm{C} 1$ at 4 equidistant points on the joint surface in sagittal and coronal CT reconstructions (a total of 8 measurements for each patient). The true CCI consisted in the mean of the 8 readings for both sides in coronal and sagittal images; with a cutoff of $4 \mathrm{~mm}$ (the CCI is highly symmetrical in children).

More recently, Gire et $\mathrm{al}^{39}$ reported a radiological study designed to evaluate diagnostic measurements, with 10 cases of TAOD and 10 cases of non-TAOD. They evaluated the sensitivity, specificity, and reliability of 8 radiographic criteria applied to CT to diagnosis TAOD. They defined 2 new measurements: the revised CCI (measured at the point of greatest separation between the occipital condyle and $\mathrm{C} 1$ lateral mass, perpendicular from the surface of the lateral mass to the surface of the occipital condyle-TAOD was diagnosed when the left and/or right CCI was $>2.5 \mathrm{~mm}$ ) and the condylar sum (which consisted of the sum of the left and right CCI and TAOD was diagnosed when $\geq 5$ $\mathrm{mm})$. The revised CCI and the condylar sum were highly sensitive $(100 \%)$, specific $(92 \%$ for condylar sum and $84 \%$ for CCI), and reliable (intraclass correlation coefficients of 0.88 and 0.93 for CCI and the condylar sum, respectively) for detecting TAOD when using a CT scan. ${ }^{39}$ The same was concluded by Dahdaleh et $\mathrm{al}^{29}$ who performed another diagnostic study using CT scans comparing the
BDI, the BAI, Lee $\mathrm{X}$-lines, Power ratio, $\mathrm{CCI}$, and revised CCI. They concluded that the revised CCI method was the most simple, sensitive, and reliable method. The high sensitivity and specificity of accessing directly the occipital-C1 joint is probably because the measurements directly assessed TAOD, whereas the other measurements were indirect evaluations. Of note, these "gold standard" CT scan measurements were not applied in any clinical series included in our systematic review, thus requiring further studies.

Martinez-del-Campo et $\mathrm{al}^{40}{ }^{40}$ in 2016 , tried to identify the normal CCI in healthy adults and compare these values with the CCI in adults with a known diagnosis of TAOD to establish more sensitive and specific cutoff values for diagnosing TAOD. They evaluated 59 adults without TAOD and 22 with TAOD, measuring thin-slice CT scans to assess the CCI, condylar sum, the Wholey and Harris intervals, the Power and Sun ratios, and the Wackenheim line and Lee X-lines. Patients without TAOD included 30 men $(50.8 \%)$ and 29 women $(49.2 \%)$ with a mean age of $42 \pm 16$ years (range, 19-87 years), and the group with TAOD comprised 10 men $(45.5 \%)$ and 12 women $(54.5 \%)$ with a mean age of $38.2 \pm 9.7$ years (range, $20-56$ years). The mean CCI obtained for non-TAOD patients was $0.89 \pm 0.12 \mathrm{~mm}$, with the largest one measuring 1.4 $\mathrm{mm}$. The mean condylar sum was $1.8 \pm 0.2 \mathrm{~mm}$, with the largest condylar sum value of $2.2 \mathrm{~mm}$. In 
patients with TAOD, the mean CCI was $3.35 \pm 0.18$ $\mathrm{mm}$ (range, $1.5-6.4 \mathrm{~mm}$ ). The shortest single CCI measurement in the TAOD patients was $1.1 \mathrm{~mm}$. Martinez-del-Campo et $\mathrm{al}^{40}$ reported that the mean condylar sum for all 22 TAOD patients was $6.7 \pm$ $2.7 \mathrm{~mm}$ and the shortest condylar sum was $3.0 \mathrm{~mm}$. After these measurements, the authors proposed new cutoff values for AOD: $1.5 \mathrm{~mm}$ for the CCI and $3.0 \mathrm{~mm}$ for the condylar sum in adults (compared with $4 \mathrm{~mm}$ in children for the CCI), with a sensitivity of 1 and false-negative rate of 0 . The sensitivities of other measurements were $0.55,0.46$, $0.27,0.23,0.41$, and 0.41 for Power, Wholey, Harris, Sun, Wackenheim, and Lee criteria, respectively.

The role of MRI in TAOD is still debated. The evaluation of ligamentous injury in MRI has supplanted any other image modality, but in the setting of a normal or near-normal CT, these findings may not be enough to indicate an OCF. Horn et $\mathrm{al}^{21}$ tried to evaluate the role of short TI inversion recovery sequences in determining cervical spine instability after trauma in 314 patients. They correlated soft tissue edema with x-rays and CT findings and concluded that when $\mathrm{CT}$ and $\mathrm{x}$-rays did not demonstrate evident instability, MRI did not provide additional information. In the Hazboun et $\mathrm{al}^{27}$ study, however, the authors reported that 7 patients (of 17 survivors, a total of $41.1 \%$ ) had normal initial cervical x-rays or CT spine scans but, due to persistent neck pain, underwent an MRI with the diagnosis of a TAOD requiring an OCF. This was also proposed by a radiological study of Corcoran et $\mathrm{al}^{41}$ that reported that CCI was not enough to diagnosis some cases of TAOD. The sensitivity used by Pang et $\mathrm{al}^{33}(4 \mathrm{~mm})$ was low and the specificity of Gire et $\mathrm{al}^{39}$ for their revised CCI $(2.5 \mathrm{~mm})$ was also low for less severe forms of TAOD but clinically significant. For these reasons, they stated the importance of MRI for complete evaluation of these patients.

Abouelleil et $\mathrm{al}^{42}$ reported an interesting case of TAOD wherein the CCI was normal, but there was severe TAOD diagnosed with an increased BDI (19 $\mathrm{mm}$ ) and atlantoaxial vertical subluxation. TAOD was clearly confirmed using an MRI, with evident apical ligamentous disruption at the craniovertebral junction $(\mathrm{CVJ})$ and $\mathrm{C} 1-\mathrm{C} 2$ distraction. They ${ }^{42}$ proposed that in the presence of $\mathrm{C} 1-\mathrm{C} 2$ dislocation, the CCI interval may not diagnose TAOD, and other measurements such as the BDI and MRI should be considered. It is important to note that the BDI cutoff for diagnosing TAOD on the basis of a sagittal CT scan is $<8.5 \mathrm{~mm}$ in 95 of 100 normal adults, compared with $12 \mathrm{~mm}$ on plain radiographs. ${ }^{43}$ We also believe that some patients with bilateral condyle avulsion may have normal CCI or revised CCI and severe forms of TAOD.

\section{Treatment Considerations-Nonoperative Management}

Horn et $\mathrm{al}^{21}$ described 5 cases treated nonoperatively based on abnormal findings on MRI but with mild or no changes evident on the CT scans. They proposed that external immobilization would be an option when there is a normal CT with mild findings on MRI, such as moderate to severe injury to posterior interspinous and atlanto-occipital ligaments and mild injury to the $\mathrm{C} 0-\mathrm{C} 1$ joints. They stated that the dilemma: to overtreat some patients with normal $\mathrm{CT}$ scan measurements but $\mathrm{C} 0-\mathrm{C} 1$ joint disruptions on MRI or not to treat them, which may lead to catastrophic neurological injuries or even death. To solve this dilemma, they proposed a classification based on 2 grades: grade 1 , characterized by normal CT scan findings but moderate MRI findings (high posterior ligaments or occipitoatlantal signal) that may be treated nonoperatively; and grade 2, minimum of 1 abnormal CT scan finding of established diagnostic criteria and grossly abnormal findings in MRI, such as in the occipitoatlantal joints, tectorial membrane, alar ligaments, or cruciate ligaments, which may be surgically fixed. It seems reasonable to not treat all patients who have only MRI findings but also to fix some patients who are at risk of a severe catastrophic injury. Although the authors did not discuss this in their study, we believe that patients with grade 1 but with spinal cord injury should be aggressively managed with OCF, similar to spinal cord injuries at any other level.

Kaplan et $\mathrm{al}^{44}$ published a literature review of nonoperative management of craniocervical ligamentous distraction injuries. They presented a case of a 27-year-old man who had severe ligamentous injury at $\mathrm{C} 0-\mathrm{C} 1$ and $\mathrm{C} 1-\mathrm{C} 2$ treated successfully with a halo for 6 months due to his poor clinical condition, with reduction and evident stability on dynamic $x$-rays and minimal symptoms at 41 months after his injury. They attributed their successful outcome to the fact that the patient probably had only incomplete injury to the main ligaments of the upper cervical spine. The outcomes 
of nonoperative management are not clear, and the risks potentially outweigh the benefits.

Child et $\mathrm{al}^{45}$ studied the craniocervical ligament's ability to prevent craniocervical distraction in a cadaveric biomechanical model using a fluoroscopic traction test and successive sectioning of the primary ligamentous complexes. Six specimens from occiput-C3 had the following ligaments sectioned to simulate a TAOD: alar, tectorial membrane, and occiput-C1 capsules. Traction was applied using 0-20 lb with fluoroscopy, and digital images analysis quantified the displacement from $\mathrm{C} 0-\mathrm{C} 1$, craniocervical excursion, and under what load a $2-\mathrm{mm}$ displacement could be reproducible. It is interesting that minimal dislocation was reported with sectioning 2 of 3 ligaments $(<2$ $\mathrm{mm})$. They reported that specimens had a firm restraint to dissociation until all 3 ligaments were cut-in an "all-or-none" restraint to instability characteristic. For these reasons, all 3 ligamentous complexes (ie, alar ligaments, tectorial membrane, and atlanto-occipital capsules) may be important to maintain stability in anatomical models and may explain why some patients may survive neurologically intact.

The commonly cited classification for TAOD published by Traynelis et $\mathrm{al}^{34}$ divided injuries in 3 types: type I (anterior dislocation of the occipital condyles in relationship with the atlas lateral masses), type II (longitudinal dislocation of the condyles), and type III (posterior dislocation of the condyles in relationship with the atlas lateral masses). ${ }^{34}$ This classification was criticized by Horn et $\mathrm{al}^{21}$ due to the potential hypermobility of these injuries, which would allow all 3 categories to be displayed in the same patient. There is also a possibility that such instability could be well positioned, and this may preclude evidencing the displacement in x-rays or CT scan. ${ }^{23}$

A significant number of studies reported other spinal injuries associated with TAOD, such as upper spinal fractures. In their series, Radcliff et al ${ }^{10}$ emphasized the high prevalence of atlantoaxial dislocations, which may or may not be associated with TAOD. In 5 cases, C1-C2 dislocations were not associated with TAOD, suggesting that separated structures stabilized the occipitoatlantal and atlantoaxial ligaments. Treatment for these associated injuries should be taken into account in a tailored approach.

\section{Treatment Considerations-Operative Management}

As already stated, the great majority of TAOD should be surgically treated as soon as possible. Although preoperative cranial traction may be used to realign the $\mathrm{CCJ}$, up to $10 \%$ neurological deterioration has been reported in the literature, which may require extreme cautions and close clinical and radiological follow-up if traction is intended. ${ }^{30}$

When operative treatment is chosen for TAOD, modern occipito-cervical fixation techniques are based on screw-rod hardware, with a high rate of fusion and immediate occipito-cervical stabilization. $^{46}$ Without associated subaxial injuries, an occipital $\mathrm{C} 2$ screw fixation is generally enough to restore CCJ stability. The $\mathrm{C} 2$ fixation can be achieved using different techniques, such as laminar, pars, pedicle, or transarticular screws, considering the patient's specific anatomy and the surgeon's experience. $^{47}$

\section{Traumatic Brain Injuries}

Because the CVJ is stable due to strong ligamentous structures, a high-energy impact is generally necessary to cause TAOD. For this reason, it is commonly associated with facial trauma and TBI, which may occult the spinal cord injury once patients present as comatose to the emergency department, which may also contribute to the delay in diagnosis in some patients. ${ }^{12,20}$ In addition, some patients may die due to TBI and not from the TAOD. ${ }^{22}$ Different types of intracranial pathology were documented in our review, such as cerebral edema, brain contusion, intraventricular hemorrhage, subdural hematoma, and the most common, $\mathrm{SAH}$, especially in the posterior fossa, which may lead to a high suspicion of AOD. ${ }^{30} \mathrm{SAH}$ in front of the pons, for instance, could lead to a high suspicion of CCJ pathology, especially because CT and MRI are made in a supine position and blood can flow up to the brain. On the other hand, cortical SAH is common in TBI and may not lead to a specific suspicion of TAOD.

Unfortunately, this review has several limitations: First, only English literature was reviewed, the quality of the included studies was not high, and we only used the PubMed database for screening. Finally, studies performed in the 1980s and 1990s may have different results from more recent studies, 
due to advances in neuroradiological exams with better anatomical details and image quality as well as improvement in surgical techniques to stabilize the occipito-cervical junction when compared with old fixation devices. We did not perform an individual analysis according to the year of the study. In spite of these limitations, we believe that our review provides a comprehensive view of TAOD that may be useful for designing future prospective studies.

\section{CONCLUSIONS}

TAOD is a devastating traumatic injury, with a high mortality rate and patients presenting as comatose in the majority of cases. There is no pathognomonic radiological diagnostic criteria, especially when CT findings are not so evident, although the CCI is promising, especially when associated with the BDI. MRI may be recommended when there are subtle findings of TAOD and a normal CT, such as SAH in the posterior fossa, upper cervical injuries, or consistent neurological findings. Surgical treatment is recommended in the majority of cases. Further studies are necessary to identify patients with mild MRI findings and TAOD who may be managed nonoperatively.

\section{REFERENCES}

1. Blackwood NJ. Atlo-occipital dislocation: a case of fracture of the atlas and axis, and forward dislocation of the occiput on the spinal column, life being maintained for thirtyfour hours and forty minutes by artificial respiration, during which a laminectomy was performed upon the third cervical vertebra. Ann Surg. 1908;47(5):654-658.

2. Joaquim AF, Patel AA. Craniocervical traumatic injuries: evaluation and surgical decision making. Global Spine $J$. 2011;1(1):37-42.

3. Tepper SL, Fligner CL, Reay DT. Atlanto-occipital disarticulation. Accident characteristics. Am J Forensic Med Pathol. 1990;11:193-197.

4. Zivot U, Di Maio VJ. Motor vehicle-pedestrian accidents in adults: relationship between impact speed, injuries, and distance thrown. Am J Forensic Med Pathol. 1993;14:185-186.

5. Gregg S, Kortbeek JB, du Plessis S. Atlanto-occipital dislocation: a case study of survival with partial recovery and review of the literature. J Trauma. 2005;58:168-171.

6. Kasliwal MK, Fontes RB, Traynelis VC. Occipito-cervical dissociation-incidence, evaluation and treatment. Curr Rev Musculoskelet Med. 2016;9:247-254.

7. Yelamarthy PKK, Chhabra HS, Vaksha V, et al. Radiological protocol in spinal trauma: literature review and Spinal Cord Society position statement. Eur Spine J. 2020;29:1197-1211.

8. Kim YJ, Yoo CJ, Park CW, Lee SG, Son S, Kim WK.
Traumatic atlanto-occipital dislocation (AOD). Korean J Spine. 2012;9(2):85-91.

9. Astur N, Klimo P Jr, Sawyer JR, Kelly DM, Muhlbauer MS, Warner WC Jr. Traumatic atlanto-occipital dislocation in children: evaluation, treatment, and outcomes. $J$ Bone Joint Surg Am. 2013;95(24):e194(1-8). doi:10.5435/JAAOS-22-05-274

10. Radcliff K, Kepler C, Reitman C, Harrop J, Vaccaro A. $\mathrm{CT}$ and MRI-based diagnosis of craniocervical dislocations: the role of the occipitoatlantal ligament. Clin Orthop Relat Res. 2012;470(6):1602-1613.

11. Joaquim AF, Ghizoni E, Tedeschi $\mathrm{H}$, et al. Upper cervical injuries: clinical results using a new treatment algorithm. J Craniovertebr Junction Spine. 2015;6(1):16-20.

12. Kenter K, Worley G, Griffin T, Fitch RD. Pediatric traumatic atlanto-occipital dislocation: five cases and a review. J Pediatr Orthop. 2001;21(5):585-589.

13. Moher D, Shamseer L, Clarke M, et al. Preferred Reporting Items for Systematic Review and Meta-Analysis Protocols (PRISMA-P) 2015 statement. Syst Rev. 2015;4:1. doi: 10.1186/2046-4053-4-1

14. Slim K, Nini E, Forestier D, Kwiatkowski F, Panis Y, Chipponi J. Methodological index for non-randomized studies (MINORS): development and validation of a new instrument. ANZ J Surg. 2003;73(9):712-716.

15. OCEBM Levels of Evidence Working Group. The Oxford 2011 Levels of Evidence. Oxford Centre for EvidenceBased Medicine. http://www.cebm.net/index.aspx?o=5653

16. Cohen A, Hirsch M, Katz M, Sofer S. Traumatic atlanto-occipital dislocation in children: review and report of five cases. Pediatr Emerg Care. 1991;7(1):24-27.

17. Bulas DI, Fitz CR, Johnson DL. Traumatic atlantooccipital dislocation in children. Radiology. 1993;188(1):155158.

18. Ahuja A, Glasauer FE, Alker GJ Jr, Klein DM. Radiology in survivors of traumatic atlanto-occipital dislocation. Surg Neurol. 1994;41(2):112-118.

19. Przybylski GJ, Clyde BL, Fitz CR. Craniocervical junction subarachnoid hemorrhage associated with atlantooccipital dislocation. Spine (Phila Pa 1976). 1996;21(15):17611768.

20. Hosalkar HS, Cain EL, Horn D, Chin KR, Dormans JP, Drummond DS. Traumatic atlanto-occipital dislocation in children. J Bone Joint Surg Am. 2005;87(11):2480-2488.

21. Horn EM, Feiz-Erfan I, Lekovic GP, Dickman CA, Sonntag VKH, Theodore N. Survivors of occipitoatlantal dislocation injuries: imaging and clinical correlates. J Neurosurg Spine. 2007;6(2):113-120.

22. Cooper Z, Gross JA, Lacey JM, Traven N, Mirza SK, Arbabi S. Identifying survivors with traumatic craniocervical dissociation: a retrospective study. J Surg Res. 2010;160(1):3-8.

23. Reis A, Bransford R, Penoyar T, Chapman JR, Bellabarba C. Diagnosis and treatment of craniocervical dissociation in 48 consecutive survivors. Evid Based Spine Care J. 2010;1(2):69-70.

24. Mueller FJ, Kinner B, Rosskopf M, Neumann C, Nerlich M, Fuechtmeier B. Incidence and outcome of atlantooccipital dissociation at a level 1 trauma centre: a prospective study of five cases within 5 years. Eur Spine J. 2013;22(1):65-71.

25. Menon KV, Al Habsi I, Al Ghafri K. Traumatic occipito-cervical dissociation in adults: a Middle Eastern cohort study. Eur J Orthop Surg Traumatol. 2018;28(3):381-387.

26. Filiberto DM, Sharpe JP, Croce MA, Fabian TC, 
Magnotti LJ. Traumatic atlanto-occipital dissociation: no longer a death sentence. Surgery. 2018;164(3):500-503.

27. Hazboun R, Muñoz A, Krafft PR, et al. Craniocervical dissociation in pediatric patients: pearls and pitfalls of diagnosis and management [published online ahead of print January 7, 2019]. Pediatr Emerg Care. doi:10.1097/PEC. 0000000000001721

28. Chang DG, Park JB, Song KJ, Park HJ, Kim WJ, Heu JY. Traumatic atlanto-occipital dislocation: analysis of 15 survival cases with emphasis on associated upper cervical spine injuries. Spine (Phila Pa 1976). 2020;45(13):884-894.

29. Dahdaleh NS, Khanna R, Menezes AH, et al. The application of the revised condyle-C1 interval method to diagnose traumatic atlanto-occipital dissociation in adults. Global Spine J. 2016;6(6):529-534.

30. Lee C, Woodring JH, Goldstein SJ, Daniel TL, Young $\mathrm{AB}$, Tibbs PA. Evaluation of traumatic atlantooccipital dislocations. AJNR Am J Neuroradiol. 1987;8(1):19-26.

31. Wholey MH, Bruwer AJ, Baker HL Jr. The lateral roentgenogram of the neck; with comments on the atlantoodontoid-basion relationship. Radiology. 1958;71(3):350-356.

32. Harris JH Jr, Carson GC, Wagner LK. Radiologic diagnosis of traumatic occipitovertebral dissociation: 1. Normal occipitovertebral relationships on lateral radiographs of supine subjects. AJR Am J Roentgenol. 1994;162(4):881-886.

33. Pang D, Nemzek WR, Zovickian J. Atlanto-occipital dislocation - part 2: the clinical use of (occipital) condyle-C1 interval, comparison with other diagnostic methods, and the manifestation, management, and outcome of atlanto-occipital dislocation in children. Neurosurgery. 2007;61(5):995-1015.

34. Traynelis VC, Marano GD, Dunker RO, Kaufman HH. Traumatic atlanto-occipital dislocation. Case report. J Neurosurg. 1986;65(6):863-870; published correction 1987;66(5):789.

35. Klimo P Jr, Ware ML, Gupta N, Brockmeyer D. Cervical spine trauma in the pediatric patient. Neurosurg Clin $N$ Am. 2007;18(4):599-620.

36. Theodore N, Aarabi BM, Dhall SS, et al. The diagnosis and management of traumatic atlanto-occipital dislocation injuries. Neurosurgery. 2013;72(3):114-126.

37. Powers B, Miller MD, Kramer RS, Martinez S, Gehweiler JA Jr. Traumatic anterior atlanto-occipital dislocation. Neurosurgery. 1979;4(1):12-17.

38. Dublin AB, Marks WM, Weinstock D, Newton TH. Traumatic dislocation of the atlanto-occipital articulation (AOA) with short-term survival. With a radiographic method of measuring the AOA. J Neurosurg. 1980;52(4):541-546.

39. Gire JD, Roberto RF, Bobinski M, Klineberg EO, Durbin-Johnson B. The utility and accuracy of computed tomography in the diagnosis of occipitocervical dissociation. Spine J. 2013;13(5):510-519.
40. Martinez-del-Campo E, Kalb S, Soriano-Baron H, et al. Computed tomography parameters for atlantooccipital dislocation in adult patients: the occipital condyle-C1 interval. $J$ Neurosurg Spine. 2016;24(4):535-545.

41. Corcoran B, Linscott LL, Leach JL, Vadivelu S. Application of normative occipital condyle-C1 interval measurements to detect atlanto-occipital injury in children. $A J N R$ Am J Neuroradiol. 2016 May;37(5):958-962.

42. Abouelleil M, Siddique D, Dahdaleh NS. Failure of the condyle-C1 interval method to diagnose atlanto-occipital dislocation in the presence of an associated atlanto-axial dislocation: a case report. Cureus. 2018;10(4):e2486. doi:10. 7759 /cureus. 2486

43. Rojas CA, Bertozzi JC, Martinez CR, et al. Reassessment of the craniocervical junction: normal values on $\mathrm{CT}$. AJNR Am J Neuroradiol. 2007;28(9):1819-1823.

44. Kaplan NB, Molinari C, Molinari RW. Nonoperative management of craniocervical ligamentous distraction injury: literature review. Global Spine J. 2015;5(6):505-512.

45. Child Z, Rau D, Lee MJ, et al. The provocative radiographic traction test for diagnosing craniocervical dissociation: a cadaveric biomechanical study and reappraisal of the pathogenesis of instability. Spine J. 2016;16(9):1116-1123.

46. Joaquim AF, Osorio JA, Riew KD. Occipitocervical fixation: general considerations and surgical technique. Global Spine J. 2020;10(5):647-656.

47. Formentin C, Andrade EJ, Maeda FL, Ghizoni E, Tedeschi H, Joaquim AF. Axis screws: results and complications of a large case series. Rev Assoc Med Bras. (1992). 2019;65(2):198-203.

Disclosures and COI: The authors do not have any conflicts of interest or financial disclosures directly related to this article content.

Corresponding Author: Andrei Fernandes Joaquim, Department of Neurosurgery, University of Campinas (UNICAMP), São Paulo, Brazil. Phone: +55(019) 35217489; Email: andjoaquim@ yahoo.com.

Published 19 August 2021

This manuscript is generously published free of charge by ISASS, the International Society for the Advancement of Spine Surgery. Copyright (C) 2021 ISASS. To see more or order reprints or permissions, see http://ijssurgery.com. 